neonatal database, babies ( $\geq 30$ weeks) born in the year 2019 were identified. This included all inborn and out-born babies transferred to the Level-3 unit for ongoing intensive care. Eligible babies were categorised into two groups based on preset criteria: 'definitely needing intensive care' (e.g., HIE, PPHN) and with diagnosis of 'respiratory distress needing intensive care'. All the data were presented as percentages or median with inter-quartile range (IQR). We used Chi-square for categorical variables and Mann Whitney test for continuous variables (SPSS). The project was registered with local hospital authorities for service evaluation.

Results During the study period, there were 78 out-born babies from Level-1 units. After excluding 34 preterm <30 weeks and 15 classified as 'definitely needing intensive care', 29 babies transferred for 'respiratory distress needing intensive care' remained. There were 154 inborn babies after excluding 22 babies 'definitely needing intensive care', 132 inborn babies were admitted for respiratory distress. 29 out-born and 132 inborn babies with similar diagnoses were analysed (table 1).

Median time of transfer for out-born babies was 9hrs 12 mins (IQR 5.5-22hrs).

Subgroup analysis of babies $>30-34$ weeks gestation, except for difference in need for mechanical ventilation $(18.5 \%$ vs $69 \%, p<0.001)$ and duration of mechanical ventilation (median 0 vs $1, \mathrm{p}<0.001$ ), there was no difference in other factors between the two groups.

Limitations included the heterogeneousness of the admission diagnosis.

Conclusions Out-born babies had higher odds of needing mechanical ventilation, developing pneumothorax, longer duration of hospital stay and longer time to reach full enteral feeds as compared to inborn babies in the Level-3 unit. The next steps are to compare the clinical characteristics of babies born in Level-1 units who were transferred out compared to those who remained in these units.

\begin{tabular}{|c|c|c|c|}
\hline & $\begin{array}{l}\text { Inborn } \\
\mathrm{N}=132\end{array}$ & $\begin{array}{l}\text { Out-Born } \\
\mathrm{N}=29\end{array}$ & Statistics \\
\hline Birth Gestation & $35(32.5-38)$ & $36(33-37)$ & 0.15 \\
\hline Birth Weight & $\begin{array}{l}2540(1770- \\
3230)\end{array}$ & $\begin{array}{l}2260(1860- \\
3210)\end{array}$ & 0.43 \\
\hline Male & $81(61 \%)$ & $18(62 \%)$ & 0.94 \\
\hline Any Antenatal Steroids & $64(48.5 \%)$ & $24(83 \%)$ & 0.001 \\
\hline C-section (Elective/Emergency) & $103(78 \%)$ & $23(82 \%)$ & 0.81 \\
\hline Apgar Score at $5 \mathrm{~min}$ & $9(8-9)$ & $9(8-9)$ & 0.47 \\
\hline Intubated at birth & $5(3.8 \%)$ & $3(10 \%)$ & 0.16 \\
\hline CPAP duration & $1(1-2)$ & $2(0-3)$ & 0.96 \\
\hline Pneumothorax & $1(0.8 \%)$ & $6(21 \%)$ & $\begin{array}{l}<0.001 \\
\text { Odds ratio: } 34 \text { (4- } \\
297)\end{array}$ \\
\hline $\begin{array}{l}\text { Need for Mechanical } \\
\text { Ventilation }\end{array}$ & $15(11.4 \%)$ & $18(62 \%)$ & $\begin{array}{l}<0.001 \\
\text { Odds ratio:12.7 (5.1- } \\
32)\end{array}$ \\
\hline $\begin{array}{l}\text { Duration of Mechanical } \\
\text { Ventilation }\end{array}$ & 0 & $1(0-2)$ & $<0.001$ \\
\hline Day of Full Enteral Feeding & $2(1-4)$ & $3(2-6)$ & 0.001 \\
\hline $\begin{array}{l}\text { Duration of stay at Level } 3 \\
\text { unit }\end{array}$ & $8(3-20)$ & $6(4-8)$ & 0.24 \\
\hline $\begin{array}{l}\text { Total Duration of Hospital } \\
\text { Stay }\end{array}$ & $8(3-20)$ & $10(7-20)$ & 0.01 \\
\hline
\end{tabular}

Association of Paediatric Palliative Medicine

\section{CARING ABOUT DEATH - PAEDIATRIC PALLIATIVE CARE SIMULATION COURSE}

${ }^{1}$ Ashish Patel, ${ }^{2}$ Annabel Copeman, ${ }^{3}$ Laura Roe, ${ }^{2}$ Stephanie Friedl, ${ }^{2}$ Sara Eacopo, ${ }^{2}$ Lucine Nahabedian, ${ }^{2}$ Ashley Holt. 'Birmingham Women's and Children's NHS Trust; ${ }^{2}$ The Royal Wolverhampton NHS Trust; ${ }^{3}$ Royal Stoke University Hospital

\subsection{6/archdischild-2021-rcpch.129}

Background Paediatric palliative care is a growing sub-speciality within paediatrics. Within England, 70\% of child deaths are from complex chronic illnesses that are life limiting, and the number of children living with these diseases is increasing.

There is a significant lack of education on paediatric palliative care for trainees in the UK. Simulation-based education could help healthcare professionals practice communication skills and management of palliative patients in safe learning environment.

Objectives I designed a simulation-based course aimed at teaching our trainees about paediatric palliative care for our region. The course learning objectives were mapped to the Royal College of Paediatrics and Child Health palliative care curriculum, as well as taking the feedback from senior trainees following a survey monkey questionnaire.

The course focused particularly on symptom management, decision making with regards of care towards the end of life, managing sensitive and complex palliative care situations, bereavement care and practical palliative care skills like prescribing and advanced care planning.

Methods We have delivered a full day course at the high fidelity simulation centre at New Cross Hospital. Give the sensitive nature, the course was aimed at senior paediatric trainees (ST4-8). As palliative care is a multidisciplinary speciality, senior nurses were invited to attend also.

The course focuses and follows the journey of a child who died from a life limiting condition, using a patient story which has been filmed to provide a parent perspective.

The course was facilitated by simulation faculty as well as paediatricians and nurses expert in paediatric palliative care. The scenarios involved a trained actor playing a simulated patient or family member. Feedback was obtained from candidates using pre and post course questionnaires which included free text comments and Likert scale questionnaires to measure confidence.

Results So far, 21 (85\% trainees, 15\% nurses) candidates have attended our paediatric palliative care courses since January 2020, one happening face to face and the other virtually. $100 \%$ of candidates felt the course met their learning objectives. All candidates rated the patient story was useful to understand more about palliative care. There was an increase in confidence intervals across all domains, with the highest changes noted for how to set up a syringe driver and prescribing drugs at the end of life. Candidates commented on an 'excellent combination of scenarios, teaching and practical sessions', with the patient story 'putting a personal face, and providing a vital parent perspective'.

Conclusions Our paediatric palliative care course is new and novel way of educating our trainees and nurses about palliative care. The course has been adapted successful to a virtual platform with the current global pandemic, not losing any vital learning for our region. We aim to continue running our course three times a year. We also hope to work 
collaboratively with the palliative care network and The CoLab Partnership to use our course to improve training across the UK and for all multidisciplinary healthcare professionals involved in paediatric palliative care

\section{British Association of Perinatal Medicine and Neonatal Society}

\section{TREATMENT OF RETINOPATHY OF PREMATURITY: COMPARATIVE ANALYSIS OF INTRAVITREAL RANIBIZUMAB VS LASER TREATMENT 7 YEARS' EXPERIENCE AT LEVEL 3 NICU, SAUDI ARABIA}

\begin{abstract}
'Ahmed Elabbasy, ${ }^{1}$ Mona Abdelbaky, ${ }^{2}$ Hassan Alshehri, ${ }^{1}$ llene Padua, ${ }^{3}$ Ahmed M Hamed, ${ }^{1}$ Abdullah Alrobaie, ${ }^{1}$ Abdulrahman Albarqi, ${ }^{1}$ Ammar Aldawalibi, ${ }^{1}$ Amer Ammari, ${ }^{1}$ Fawaz Kashlan. ${ }^{1}$ Prince Sultan Military Medical City; ${ }^{2}$ College of Medicine, Al Imam Mohammad Ibn Saud Islamic University (IMSIU), Riyadh, Saudi Arabia; ${ }^{3}$ Collage of Medicine, Alfaisal University, Riyadh, Saudi Arabia
\end{abstract}

\subsection{6/archdischild-2021-rcpch. 130}

Background Retinopathy of prematurity (ROP) is a vasoproliferative disorder which affects eyes of premature infants. Conventional laser photocoagulation and anti-vascular endothelial growth factors (anti-VEGF) like Ranibizumab are used for ROP treatment.

Objectives To compare the efficacy of Intravitreal Ranibizumab (IVR) to laser photocoagulation for treatment of ROP

Methods Very Low Birth Wight (VLBW) infants born at Prince Sultan Military Medical City, Riyadh, Saudi Arabia were enrolled during 7 years period from January 2011 to December 2017. Screening criteria for ROP were infants who were born at gestational age of less than 32 weeks and/or had birth weight of $<1500 \mathrm{~g}$ or unstable clinical course. From January 2011 till June 2014 the standard treatment was laser photocoagulation. We started IVR treatment for ROP from July 2014. Patients in either group (laser group and IVR group) were candidates for treatment in case they develop type 1 ROP.

Results During study period, 1315 infants were screened for ROP, 183 infants developed ROP (13.9\%) and 35 infants out of 183 received treatment. A total of 69 eyes from 35 infants were included in the study and analyzed. Ranibizumab group included 21 infants (42 eyes). Laser group included 27 eyes from 14 infants.

It was observed that 36 out of 42 eyes showed regression of ROP in IVR group whereas all the 27 eyes treated with laser showed regression of ROP in laser group (P 0.09). There was significant difference in recurrence of ROP in both groups with 12 eyes (28.6\%) showing recurrence of ROP in IVR group compared to 1 eye $(3.7 \%)$ in Laser group (P 0.01). In IVR group, 8 eyes required second dose of IVR and 10 eyes required laser treatment which were significantly higher than laser group wherein no infants required either IVR or laser ( $\mathrm{p} 0.02$ and 0.01 respectively). No significant difference was found in both groups in terms of refractive error, and anisometropia. Squint incidence was significantly higher in laser group (29.6\%) versus IVR group $(4.8 \%)(\mathrm{P}=$ $0.01)$.

Conclusions Overall data suggests that IVR showed decreased rate of ROP regression as compared to laser. Moreover, significant recurrence of ROP was observed after IVR treatment as compared to laser treatment. More extensive and careful follow up are needed to monitor regression and recurrence of ROP after IVR treatment.

\section{Quality Improvement and Patient Safety}

\section{IMPROVING AWARENESS OF STAFF WELLBEING IN A PAEDIATRIC HAEMATOLOGY AND ONCOLOGY UNIT}

Shona Johnston, Amy Mitchell, Joanna Craven, Laura Mitchell. Oxford University Hospitals NHS Foundation Trust

\subsection{6/archdischild-2021-rcpch.131}

Background Healthcare staff wellbeing has never been such a priority. The Covid pandemic has impacted our lives personally and professionally.

Objectives To increase awareness of and engagement in wellbeing within a paediatric haematology and oncology unit.

Methods We undertook a number of PDSA wellbeing projects from September 2020. These included:

- A wellbeing email (initially twice weekly) to all departmental and support services staff, including non-clinical staff.

- A 'Celebrate the Small Things' board for staff messages.

- A 'HALT' (hungry, angry, late and tired) box to encourage breaks and sustenance.

- A Christmas celebration of our staff, based on an online survey; highlighting team and individual strengths.

We undertook an online survey, requesting feedback on the length, content and frequency of wellbeing emails, and requesting further qualitative feedback on the project.

Results Since September 2020, 31 wellbeing emails have been sent out to 75 members of our department, including medical, nursing, support and secretarial staff. Content is varied and includes videos, coaching-type questions, articles and challenges. Themes include civility, gratitude, finding joy, mental health resources, humour, acknowledging and validating our difficult job, and valuing colleagues. As a marker for 'engagement', 29 emails have been received back in response.

There have been 27 messages added to our celebration board.

Our Christmas celebration highlighted 27 individuals, and acknowledged the work of the Wellbeing Team. Individuals were sent an email certificate. Comments specific to the wellbeing team included, 'Thank you for recognising the need and taking time to care for us all' and 'I think both the wellbeing emails and promotion of wellbeing has been fantastic. What may seem like a nice little email can have a huge impact not just on people's wellbeing but has as a knock on effect their motivation, productivity and general output.'

Eleven staff completed our survey (15\% response rate); $72 \%$ rated the emails as 'very' or 'extremely' helpful. All responders felt the emails were the right length. $63 \%$ felt they were the right frequency, with $36 \%$ feeling they were too frequent. Comments on the project were overwhelmingly positive; they included 'simply knowing that there is someone (some people) who care about us and want to make this a more positive environment $\mathrm{J}$ also, the content is great!' and 'I think it is great to raise the wellbeing agenda, such an important and overlooked area.' 